\title{
Aluminio en pacientes con terapia de reemplazo renal crónico con hemodiálisis en dos unidades renales en Bogotá
}

Aluminium in chronic renal replacement therapy patients undergoing haemodialysis in two renal units in Bogotá

Omayda Cárdenas $^{1}$, Omar Segura ${ }^{1,5}$, William Puentes ${ }^{2}$, Mauricio Sanabria ${ }^{3}$, Gerardo Nava ${ }^{1}$ y Rubén Torrenegra ${ }^{4}$

1 Instituto Nacional de Salud, Bogotá, D.C., Colombia. ocardenas@ins.gov.co, gnavat@ins.gov.co 2 AGAT Laboratorios, Montreal, Canadá.william30s@hotmail.com

3 Renal Therapy Services Limitada, Baxter, Bogotá, D.C., Colombia. mauricio_sanbria@baxter.com 4 Facultad de Química, Pontificia Universidad Javeriana, Bogotá, D.C., Colombia. rtorrene@javeriana.edu.co

5 Segura Morón \& Castañeda Asesores en Salud Ltda. osegura@smc-as.com

Recibido 5 Enero 2010/Enviado para Modificación 24 Octubre 2010/Aceptado 29 Octubre 2010

\section{RESUMEN}

Objetivo Determinar las concentraciones de aluminio en suero de pacientes con terapia de reemplazo renal crónico con hemodiálisis y las concentraciones en agua de redes de distribución y diálisis en dos unidades renales en Bogotá.

Material y Métodos Estudio descriptivo en 63 pacientes en hemodiálisis y 20 individuos sanos. Las concentraciones de aluminio se determinaron por espectrofotometría de absorción atómica horno de grafito con corrección de lámpara de deuterio.

Resultados El promedio de las concentraciones de aluminio en suero de los pacientes fue de $26,5 \mu \mathrm{g} / \mathrm{L}$ (11,2 a 49,2 $\mu \mathrm{g} / \mathrm{L}, \mathrm{DE}=8,03)$, en individuos sanos de 8,05 $\mu \mathrm{g} / \mathrm{L}$ (menor al Límite de Detección a 17,2 $\mu \mathrm{g} / \mathrm{L}, \mathrm{DE}=4,31$ ), en agua de diálisis fue menor a $2 \mu \mathrm{g} / \mathrm{L}$ y en agua de las redes de distribución menor a $200 \mu \mathrm{g} / \mathrm{L}$.

Conclusiones Las concentraciones de aluminio en el agua de la red de distribución y diálisis estudiadas se encontraron por debajo de los valores establecidos internacionalmente indicando un adecuado tratamiento de las mismas. Igualmente las concentraciones de aluminio pre-HD y post-HD observadas en los pacientes se encontraron por debajo de las reportadas en la literatura. El consumo de hidróxido de aluminio aumenta significativamente la concentración de aluminio en suero. Variables como edad, género, estado civil y situación laboral no son factores de riesgo que alteren significativamente las concentraciones de aluminio en suero.

Palabras Clave: Aluminio, diálisis renal, insuficiencia renal crónica (fuente: DeCS, BIREME).

\section{ABSTRACT}

Objective Determining aluminium concentrations in the serum of patients undergoing chronic renal replacement therapy with haemodialysis and concentration in distribution network water and dialysis in two renal units in Bogotá. 
Material and Methods This was a descriptive study of 63 haemodialysed patients and 20 healthy subjects. Aluminium concentration was determined in water and serum using graphite furnace atomic absorption spectrometry with deuterium lamp background corrector.

Results Average aluminium concentration was $26.5 \mu \mathrm{g} / \mathrm{L}$ in patients (ranging from 11.2 to $49.2 \mu \mathrm{g} / \mathrm{L} ; 8.03$ standard deviation) and $8.05 \mu \mathrm{g} / \mathrm{L}$ in healthy individuals (ranging from undetectable to $17.2 \mu \mathrm{g} / \mathrm{L} ; 4.31$ standard deviation). Aluminium concentration in dialysis water and distribution network water was below $2 \mu \mathrm{g} / \mathrm{L}$ and $200 \mu \mathrm{g} / \mathrm{L}$, respectively.

Conclusions Aluminium concentration in water and serum in this study was below international standard values, thereby indicating appropriate treatment. Additionally, aluminium concentration in pre-HD and post-HD sera was below that reported previously. Aluminium hydroxide uptake increases aluminium concentration in serum. Personal situation regarding age, gender, civil and work status were not risk factors determining aluminium concentrations in serum.

Key Words: Aluminium, renal dialysis, chronic renal insufficiency (source: $M e S H$, NLM).

$\mathrm{L}$

a alta concentración de aluminio en el agua de diálisis está relacionada con su presencia en tejidos cerebrales y óseos de pacientes con enfermedad renal en diálisis $(1,2)$, lo cual es una amenaza en países en desarrollo (3-5). Durante la forma epidémica reportada en los años 70 con encefalopatía y osteodistrofia fracturante incapacitante se demostraron los efectos de la acumulación de este metal en el organismo con consecuencias tales como fracturas óseas, especialmente en costillas y pelvis, enfermedad ósea, miopatía proximal invalidante, hipofunción paratiroidea, anemia microcítica y miocardiopatía, encefalopatía por diálisis, demencia progresiva y muerte $(3,6-$ 9). La tecnología en el control del líquido de diálisis ha mejorado de forma notable en las últimas décadas; no obstante, la difusión no selectiva de toxinas y sustancias a través de las membranas de diálisis representan todavía un riesgo para los pacientes en hemodiálisis, generando una situación de alerta, principalmente en lugares con tratamientos de agua inapropiados. En Bogotá existen unidades renales con alto número de pacientes en hemodiálisis, limitaciones en la monitorización de las concentraciones de aluminio en suero y ausencia de vigilancia del metal en agua de redes y de diálisis. El presente estudio es el primero en Colombia que describe una valoración de la exposición a aluminio en dichos pacientes y de las concentraciones de aluminio en agua de redes y de diálisis. 


\section{MATERIAL Y MÉTODOS}

Muestra de estudio

En 2008 se realizó un estudio descriptivo transversal en 83 participantes (63 pacientes con terapia de reemplazo renal crónico con hemodiálisis y 20 individuos sanos) de dos unidades renales en Bogotá, muestra calculada por muestreo aleatorio simple, asumiendouna prevalencia reportada en la literatura del $0,041 \%(10,11)$. El tamaño muestral se obtuvo con un poder del $80 \%$, un nivel de significancia del $95 \%$ y un $5 \%$ de pérdidas. Los criterios de inclusión fueron llevar mínimo 3 años en hemodiálisis, y para los individuos sanos no tener problemas de salud relacionados con falla renal.

Recolección de la información y toma de la muestra de sangre

Los pacientes firmaron consentimiento escrito y respondieron una entrevista sobre información demográfica, proceso de hemodiálisis, antecedentes familiares y clínicos presentados durante el tratamiento y hábitos alimentarios y estilos de vida. Se tomaron dos muestras de $5 \mathrm{~mL}$ de sangre, una pre-hemodiálisis (preHD) y otra post-hemodiálisis (post-HD) el mismo día. La muestra fue tomada de la línea arterial de la fístula arterio-venosa o del catéter, recolectando la sangre en tubos Corning® de poliestireno cristalino estériles, libres de contaminación con aluminio $(9,12,13)$; en los individuos sanos la sangre se tomó por punción venosa. Las muestras permanecieron refrigeradas hasta su análisis. Se dio cumplimiento a las disposiciones vigentes para investigación en salud en humanos $(14,15)$.

Determinación de las concentraciones de aluminio en suero

Se realizó espectrofotometría de absorción atómica-horno de grafito con corrector de lámpara de deuterio a 309,3 nm, empleando un equipo Perkin Elmer 2380 equipado con un horno de grafito HGA-400 y un automuestreador AS-40, según método de Nackowski (16), adaptado en el Instituto Nacional de Salud de Colombia (INS). En el procedimiento analítico se incluyeron muestras de referencia del Centro Toxicológico de Québec (CTQ), Canadá, por cada lote de muestras procesadas. La precisión de los análisis de aluminio en suero fue rutinariamente monitoreada por el uso de un programa de control de calidad interno y externo (Interlaboratory Comparison Program for Metals in Biological Matrices, Institut Nacional de Santé Publique, Centre de Toxicologie, Québec, Canada). 
Determinación de concentraciones de aluminio en agua

Se tomaron muestras de las redes de distribución y del agua para diálisis; se dejó salir el agua de la llave del punto de toma durante 10 segundos y se recolectó en tubos Falcon ${ }^{\circledR}$ de poliestireno cristalino. Las muestras permanecieron en refrigeración hasta su análisis. La determinación de aluminio se realizó por espectrofotometría de absorción atómica-horno de grafito con corrector de lámpara de deuterio a 309,3 nm, según el método de FernándezMartín (12) y García (17), adaptado en el INS. El programa del horno de grafito para el método en aguas fue igual al empleado para suero, excepto que la temperatura de limpieza fue de $2.750^{\circ} \mathrm{C}$. El procedimiento analítico de aluminio en agua se hizo incluyendo soluciones estándar de un patrón certificado de trazas de metales, Ref. QCI-016-1, Lot. 002076, solvente (Matriz): 5\% ácido nítrico de $504 \mathrm{ppb}$ de aluminio $(\mu \mathrm{g} / \mathrm{L})$. Las soluciones estándar preparadas obedecían a concentraciones entre 5 y $200 \mathrm{ppb}(\mu \mathrm{g} / \mathrm{L})$, considerando que para los líquidos de diálisis la curva es lineal hasta $40 \mathrm{ppb}(\mu \mathrm{g} / \mathrm{L})$ y para la interpolación de las absorbancias de las aguas de la red de distribución se requerían concentraciones entre 40 y $200 \mathrm{ppb}(\mu \mathrm{g} / \mathrm{L})$. Para la preparación de los estándares y diluciones de las muestras de suero, se empleó agua ultrapura (18,2 M $\Omega . c m)$ obtenida del sistema Milli-Q PLUS System (Millipore Corporation).

\section{Análisis estadístico}

Se realizó análisis descriptivo mediante frecuencias simples, medidas de tendencia central y dispersión con Epi Info 6.04 (Centers for Disease Control \& Prevention-CDC, USA; World Health Organization, Geneva, Switzerland). Las concentraciones séricas de aluminio se transformaron a variable nominal dicotómica con base en los valores de referencia en población adulta "normalmente sana" $(2,0$ a $14 \mu \mathrm{g} / \mathrm{L})$, reportados en la literatura $(2,18,19)$. Con base en lo anterior, se tomaron como valores normales de aluminio los menores o iguales a $14 \mu \mathrm{g} / \mathrm{L}$ y como valores anormales, los mayores a este valor. Para establecer la relación entre la media de las concentraciones de aluminio en suero y las diferentes variables se utilizaron modelos de regresión lineal y logística. Finalmente, se realizó un análisis estratificado (método de Mantel y Haenszel) para comprobar que ninguna de las posibles asociaciones encontradas fuera el resultado de la interacción de otras variables. 


\section{RESULTADOS}

Concentraciones de aluminio en agua de redes de distribución y de diálisis en unidades renales

La concentración promedio de aluminio en agua de la red de distribución de la unidad renal 1 fue de $158,1 \mu \mathrm{g} / \mathrm{L}$ (mediana=152,6 $\mu \mathrm{g} / \mathrm{L}, \mathrm{DE}=8,4$ ), en la segunda muestra tomada en el tanque de pre-tratamiento (pre-ósmosis) fue de $81,4 \mu \mathrm{g}$ / $\mathrm{L}$ (mediana $=85,0 \mu \mathrm{g} / \mathrm{L}, \mathrm{DE}=10,6$ ), y en la tercera muestra después del proceso con ósmosis inversa (agua para el concentrado de diálisis que se pone en contacto con los pacientes), fue de $1,2 \mu \mathrm{g} / \mathrm{L}$ (mediana $=1,2 \mu \mathrm{g} / \mathrm{L}, \mathrm{DE}=0,24)$. En la unidad renal 2 la concentración promedio en agua de la red de distribución fue de $149,6 \mu \mathrm{g} / \mathrm{L}$ (mediana=149,8 $\mu \mathrm{g} / \mathrm{L}, \mathrm{DE}=3,8$ ). Allíse tomaron dos muestras en la etapa del proceso de ósmosis (ósmosis y post-ósmosis) presentando concentraciones menores al límite de detección del método $(<\mathrm{LD})$.

Concentraciones de aluminio en suero de individuos sanos

Los 20 individuos sanos (10 hombres y 10 mujeres) entre 24 y 73 años (media $=42,4, \mathrm{DE}=13,6)$ mostraron concentraciones promedio de $8,05 \mu \mathrm{g} / \mathrm{L}(<\mathrm{LD}$ a $17,2 \mu \mathrm{g} / \mathrm{L}$, mediana $=6,27 \mu \mathrm{g} / \mathrm{L}$ y $\mathrm{DE}=4,31)$. Los hombres con concentraciones entre $<\mathrm{LD}$ y $17,2 \mu \mathrm{g} / \mathrm{L}$ (media=6,8 $\mu \mathrm{g} / \mathrm{L}, \mathrm{DE}=4,3$ ) y las mujeres entre 3,8 y 15,6 $\mu \mathrm{g} / \mathrm{L}$ (media $=9,2 \mu \mathrm{g} / \mathrm{L}, \mathrm{DE}=4,1$ ). Hubo diferencias significativas de las concentraciones entre participantes con ingesta de hidróxido de aluminio en los últimos tres meses, y aquellos sin ésta $(p=0,03)$. No hubo diferencias significativas relacionadas con variables sociodemográficas, antecedentes clínicos familiares, hábitos alimentarios o estilos de vida $(p>0,05)$.

Características demográficas de los pacientes en hemodiálisis

De los 63 pacientes el 60,3\% eran hombres y el 39,7\% mujeres entre 21 y 89 años (media $=52,7, \mathrm{DE}=18,3$ ). Los hombres entre 22 y 89 años (media $=54,8$ y $\mathrm{DE}=19,0$ ) y las mujeres entre 21 y 80 años (media 49,7 y $\mathrm{DE}=16,9$ ); la Tabla 1 muestra las variables sociodemográficas. Se encontraron diferencias significativas entre las concentraciones de aluminio en suero pre-HD de los pacientes, por unidad renal $(p=0,02)$, por género $(p=0,02)$ y por tomar o no hidróxido de aluminio $(p=0,04)$, pero no por edad, estado civil, nivel educativo, tiempo de tratamiento con hemodiálisis, número de sesiones semanales y tiempo por sesión $(p>0,05)$. 
Información relacionada con el proceso de hemodiálisis y toma de medicamentos

El tiempo promedio de tratamiento con hemodiálisis fue de 86,7 meses (rango 36 a 240 meses, DE=45,4). El 98,4 \% (62) pacientes acudían a 3 sesiones semanales (tiempo por sesión de 3 horas 20 minutos a 5 horas), siendo en la mayoría de los casos $(63,5 \%)$ de 4 horas, seguido por el de 3 horas $30 \mathrm{~min}$. (19,0\%) y de 4 horas $30 \mathrm{~min} .(6,3 \%)$. En el 92,1\% (58) de los pacientes el cumplimiento en el tratamiento fue del $100 \%$. El $100 \%$ de los pacientes tomaban medicamentos para el control de la hipertensión y de la anemia, el 60,3\% analgésicos, el 38,1 \% para control de colesterol y otras grasas, el 73,0 \% antiácidos o coagulantes de fosfatos a base de carbonato, el 57,1\% para control de úlceras pépticas, el 41,3\% vitaminas del complejo B y el 11,1\% para el control de glicemia entre otros. Un paciente reportó la toma de hidróxido de aluminio de rutina, quien presentó concentraciones de aluminio en suero pre-HD de $36,8 \mu \mathrm{g} / \mathrm{L}$. El 12,7 \% de los pacientes que consumieron hidróxido de aluminio en los últimos tres meses, presentaron concentraciones promedio de aluminio en suero pre-HD de $31,4 \mu \mathrm{g} / \mathrm{L}$ (mediana=32,3 $\mu \mathrm{g} / \mathrm{L}, \mathrm{DE}=5,5$ ) y en suero post-HD de $27,1 \mu \mathrm{g} / \mathrm{L}$ (mediana $=25,6 \mu \mathrm{g} / \mathrm{L}, \mathrm{DE}=5,1$ ) y en los que no lo consumieron fueron de $25,8 \mu \mathrm{g} / \mathrm{L}$ (mediana $=25,0 \mu \mathrm{g} / \mathrm{L}, \mathrm{DE}=8,1$ ).

Tabla 1. Variables sociodemográficas de los pacientes en hemodiálisis, Bogotá, 2008

\begin{tabular}{lcc}
\hline Característica & Frecuencia & $\%$ \\
\hline Total pacientes por UR & 21 & 33,3 \\
Unidad Renal 1 & 42 & 66,7 \\
Unidad Renal 2 & & \\
Edad & 13 & 20,6 \\
$20-35$ & 17 & 27,0 \\
$36-50$ & 15 & 23,8 \\
$51-65$ & 16 & 25,4 \\
$66-80$ & 2 & 3,2 \\
$81-95$ & 38 & \\
Género & 25 & 60,3 \\
Hombres & 32 & 39,7 \\
Mujeres & 20 & 50,8 \\
Estado civil & 4 & 31,7 \\
Casado & 2 & 6,3 \\
Soltero & 5 & 3,2 \\
Viudo & & 7,9 \\
Divorciado & 22 & 34,9 \\
Union libre & 34 & 54,0 \\
Nivel educativo & 7 & 11,1 \\
Primaria & & 15,9 \\
Secundaria & 10 & 46,0 \\
Superior & 29 & 38,1 \\
\hline Situación laboral & 24 & \\
Activo & & \\
Pensionado & & \\
Beneficiario-Inactivo & & \\
\hline Fuente: Encuesta aplicada a los pacientes en hemodiálisis-Grupo \\
Salud Ambiental-SRNL, Instituto Nacional de Salud, 2008 \\
\hline
\end{tabular}


Información relacionada con antecedentes clínicos y familiares de los pacientes

Un paciente con enfermedad de Alzheimer presentó concentración de aluminio en suero pre-HD de 49,2 $\mu \mathrm{g} / \mathrm{L}$; los demás tuvieron concentración promedio de aluminio en suero pre-HD de 26,2 $\mu \mathrm{g} / \mathrm{L}$. El 11,1 \% refirió algún tipo de anemia en miembros de sus familias; en estos pacientes la concentración sérica de aluminio fue mayor $(28,3 \mu \mathrm{g} / \mathrm{L})$ a los que no refirieron este antecedente $(26,3$ $\mu \mathrm{g} / \mathrm{L}) .21$ pacientes en hemodiálisis $(33,3 \%)$ manifestaron dolor óseo en las articulaciones, cadera, hombros, manos y rodillas; $27 \%$ (17) refirió dificultad para caminar por artralgia y astenia, y 30,2 \% (19) reportó trastornos de memoria. Las concentraciones de aluminio en pacientes que refirieron trastornos de memoria $(27,8 \mu \mathrm{g} / \mathrm{L})$, dificultad para hablar $(39,8 \mu \mathrm{g} / \mathrm{L})$ y para la marcha $(29,8 \mu \mathrm{g} / \mathrm{L})$ fueron mayores a los que no manifestaron estos signos o síntomas $(25,9 \mu \mathrm{g} / \mathrm{L}, 26,1 \mu \mathrm{g} / \mathrm{L}$ y $25,3 \mu \mathrm{g} / \mathrm{L})$, respectivamente. No hubo diferencias significativas entre concentraciones de aluminio en suero pre-HD y presentar o no antecedentes clínicos y familiares como enfermedades neurodegenerativas, anemia, osteoporosis o problemas renales $(p>0,05)$. Tampoco hubo diferencias significativas entre los que presentaban o no signos o síntomas durante el tratamiento con hemodiálisis, o el haber tenido algún tipo de cirugía con implantes metálicos $(p>0,05)$.

Hábitos alimentarios y estilos de vida de los pacientes

La Tabla 2 muestra el consumo de alimentos y algunos estilos de vida que pueden estar relacionados con la ingesta de aluminio. El 4,8\% de los pacientes manifestaron fumar 1 a 10 cigarrillos/día, presentando concentraciones promedio de aluminio de $35,1 \mu \mathrm{g} / \mathrm{L}$ vs. $26,0 \mu \mathrm{g} / \mathrm{L}$ en los que no refirieron esto; el 95,2 \% (60) reportaron uso de utensilios de aluminio para preparar alimentos, el 51,7 \% (31) dejaban los alimentos en estos utensilios, alcanzando concentraciones de aluminio de $27,3 \mu \mathrm{g} / \mathrm{L}$ vs. $25,8 \mu \mathrm{g} / \mathrm{L}$ en los que no los usaban. No hubo diferencias significativas entre las concentraciones séricas de aluminio de los pacientes que refirieron consumo o no de alimentos (té, café, suplementos minerales, agua), tener o no algunos hábitos - consumo de alcohol, uso de antitranspirantes y uso de utensilios de aluminio para preparar los alimentos- $(p>0,05)$.

Concentraciones séricas de aluminio en pacientes en hemodiálisis

En suero pre-HD el rango de concentración de aluminio estuvo entre 11,2 y $49,2 \mu \mathrm{g} / \mathrm{L}$ (media=26,5 $\mu \mathrm{g} / \mathrm{L}, \mathrm{DE}=8,03$ ) y en suero post-HD fue de 9,6 a 40,9 $\mu \mathrm{g} / \mathrm{L}$ (media $=21,8 \mu \mathrm{g} / \mathrm{L}, \mathrm{DE}=6,9)$. Los hombres presentaron concentraciones 
séricas de aluminio entre 11,2 y $44,7 \mu \mathrm{g} / \mathrm{L}$ (media $=28,2 \mu \mathrm{g} / \mathrm{L}, \mathrm{DE}=7,8$ ) y las mujeres entre 11,9 y 49,2 $\mu \mathrm{g} / \mathrm{L}$ (media=23,9 $\mu \mathrm{g} / \mathrm{L}, \mathrm{DE}=7,7$ ). En el análisis estratificado, no hubo diferencia significativa entre los pacientes que presentaban concentraciones de aluminio en suero pre-HD mayores a $14 \mu \mathrm{g} / \mathrm{L}$ y los que tenían concentraciones de aluminio menores a este valor, ajustando por las variables sociodemográficas, familiares, clínicas, relacionadas a hemodiálisis, hábitos alimentarios y estilos de vida $(p>0,05)$.

Tabla 2. Hábitos alimentarios, estilos de vida y concentraciones de aluminio de los pacientes en hemodiálisis, Bogotá, 2008

\begin{tabular}{|c|c|c|c|}
\hline Características & Frecuencia & $\%$ & $\begin{array}{c}\text { Concentraciones } \\
\text { de aluminio }(\mu \mathrm{g} / \mathrm{L})\end{array}$ \\
\hline $\begin{array}{l}\text { Consumo de café } \\
\text { Sí } \\
\text { No }\end{array}$ & $\begin{array}{c}54 \\
9\end{array}$ & $\begin{array}{l}85,7 \\
143\end{array}$ & $\begin{array}{l}27,4 \\
26,4\end{array}$ \\
\hline $\begin{array}{c}\text { Consumo de té } \\
\text { Sí } \\
\text { No }\end{array}$ & $\begin{array}{l}10 \\
53\end{array}$ & $\begin{array}{l}15,9 \\
84,1\end{array}$ & $\begin{array}{l}30,3 \\
25,8\end{array}$ \\
\hline $\begin{array}{l}\text { Consumo de antiácidos } \\
\text { Sí } \\
\text { No }\end{array}$ & $\begin{array}{c}8 \\
55\end{array}$ & $\begin{array}{l}12,7 \\
87,3\end{array}$ & $\begin{array}{l}31,4 \\
25,8\end{array}$ \\
\hline $\begin{array}{l}\text { Suplementos minerales } \\
\text { Sí } \\
\text { No }\end{array}$ & $\begin{array}{c}9 \\
54\end{array}$ & $\begin{array}{l}14,3 \\
85,7\end{array}$ & $\begin{array}{l}26,1 \\
26,6\end{array}$ \\
\hline $\begin{array}{l}\text { Consumo de agua } \\
\text { Sí } \\
\text { No }\end{array}$ & $\begin{array}{l}38 \\
25\end{array}$ & $\begin{array}{l}60,3 \\
39,7\end{array}$ & $\begin{array}{l}26,1 \\
25,7\end{array}$ \\
\hline $\begin{array}{l}\text { Consumo de alcohol } \\
\text { Sí } \\
\text { No }\end{array}$ & $\begin{array}{c}9 \\
54\end{array}$ & $\begin{array}{l}14,3 \\
85,7\end{array}$ & $\begin{array}{l}27,7 \\
26,3\end{array}$ \\
\hline $\begin{array}{l}\text { Fuma } \\
\text { Sí } \\
\text { No }\end{array}$ & $\begin{array}{c}3 \\
60\end{array}$ & $\begin{array}{c}4,8 \\
95,2\end{array}$ & $\begin{array}{l}35,1 \\
26,0\end{array}$ \\
\hline $\begin{array}{l}\text { Uso de } \\
\text { antitranspirantes } \\
\text { Sí } \\
\text { No }\end{array}$ & $\begin{array}{l}34 \\
29\end{array}$ & $\begin{array}{l}54,0 \\
46,0\end{array}$ & $\begin{array}{l}27,5 \\
25,6\end{array}$ \\
\hline $\begin{array}{l}\text { Deja alimentos en } \\
\text { utensilios de aluminio } \\
\text { Sí } \\
\text { No }\end{array}$ & $\begin{array}{l}30 \\
33\end{array}$ & $\begin{array}{l}47,6 \\
52,4\end{array}$ & $\begin{array}{l}27,2 \\
25,9\end{array}$ \\
\hline
\end{tabular}

Fuente: Encuesta aplicada a los pacientes en hemodiálisis-Grupo Salud Ambiental-SRNL, Instituto Nacional de Salud, 2008

\section{DISCUSION}

La toxicidad del aluminio es uno de los problemas más significativos en los pacientes con insuficiencia renal crónica (IRC) sometidos a hemodiálisis (12). 
El metal entra al organismo a través de alimentos, medicamentos y agua potable. Hace dos décadas las soluciones de diálisis y los medicamentos que contenían aluminio fueron las principales fuentes de exposición en los pacientes con IRC, quienes tienen un elevado riesgo de acumulación de metales como consecuencia de la ausencia de función renal, principal vía de eliminación de muchos de ellos $(4,5,8,17)$. La concentración promedio de aluminio en los 20 sujetos sanos estudiados fue de $8,05 \mu \mathrm{g} / \mathrm{L}$ ( $<\mathrm{LD}$ a $17,2 \mu \mathrm{g} / \mathrm{L})$, menor a la reportada en estudios internacionales $(10 \mu \mathrm{g} / \mathrm{L})(16,18-20)$. Es necesario confirmar estos hallazgos con posteriores estudios, por ser una primera aproximación a nivel nacional en el tema.

Revisadas las concentraciones de aluminio en agua de las redes de las dos unidades renales, se encontraron dentro de los valores aceptables establecidos para la concentración de aluminio en agua para consumo humano, según la normativa adoptada por Colombia, por la OMS según su valor guía y por la Farmacopea Europea (21-25). Las concentraciones de aluminio halladas en el agua post-tratamiento con ósmosis inversa -empleada para preparar los fluidos de diálisis- fueron menores a $2 \mu \mathrm{g} / \mathrm{L}$, inferiores a los valores límites permisibles establecidos por la Asociación para el Avance de la Instrumentación Médica $(22,26)$ y por el Instituto Nacional de Estándares Americanos (27), recomendaciones adoptadas en el país (28). Adicionalmente, estas concentraciones fueron menores a las reportadas en la literatura $(5 \mu \mathrm{g} / \mathrm{L})(18)$, sugiriendo que el procedimiento realizado en las unidades renales participantes cumple con la normativa.

La concentración promedio de aluminio en suero pre-HD $(26,5 \mu \mathrm{g} / \mathrm{L})$, fue muy inferior a la reportada en la literatura para pacientes en hemodiálisis (entre $30 \mu \mathrm{g} / \mathrm{L}$ y $55 \mu \mathrm{g} / \mathrm{L})(5,29-33)$; se encontró reducción de las concentraciones de aluminio post-HD después de la sesión de diálisis, coincidiendo con lo reportado en la literatura $(5,22,34,35)$. Igual a lo reportado $(36,37)$, se observó que la edad, género, situación laboral y estado civil de los participantes no son factores de riesgo significativos que determinen las concentraciones de aluminio en suero.

Las concentraciones de aluminio en suero fueron más altas en los participantes que informaron preparar y almacenar los alimentos en utensilios de aluminio frente a aquellos que no; empero, las diferencias no fueron significativas $(p>005)$. Algunos estudios reportaron el desprendimiento del aluminio de estos utensilios, su transferencia a los alimentos y a las personas que los consumen $(1,3,21,38,39)$. El uso de recipientes de aluminio para la 
preparación de alimentos ácidos es una fuente exógena de exposición al metal ya que los ácidos disuelven el aluminio. Al limpiar los recipientes con tratamientos abrasivos se provoca el desprendimiento de la película protectora de óxido de aluminio y se genera así contaminación. El aluminio ingerido a partir de los alimentos, al igual que el proveniente del agua para consumo, representan la mayor fuente de exposición a este metal para la población general $(22,23)$.

Hubo diferencias significativas entre concentraciones de aluminio pre-HD de los pacientes por género $(p=0,01)$. Es de anotar que los hombres presentaron concentraciones más altas que las mujeres (31,4 $\mu \mathrm{g} \mathrm{Al} / \mathrm{L}$ vs. 23,9 $\mu \mathrm{g} \mathrm{Al} / \mathrm{L})$, lo cual podría ser explicado porque los ocho pacientes que refirieron el consumo de hidróxido de aluminio eran hombres. Esto sugiere que el consumo de medicamentos que contienen aluminio puede contribuir a su incorporación vía gastrointestinal, incrementando los depósitos de aluminio en hueso y por ende sus concentraciones en suero $(21,40,41)$. La diferencia de concentraciones de aluminio puede explicarse mejor por factores externos como el consumo de hidróxido de aluminio: tras el análisis estratificado por género no hubo diferencias significativas entre aquellos con concentraciones mayores de $14 \mu \mathrm{g} / \mathrm{L}$ y los que estaban por debajo de este valor $(p=0,7)$. Se observó que los pacientes que tomaron este medicamento como antiácido presentaron concentraciones de aluminio mayores a los que no lo consumían $(31,4 \mu \mathrm{g} / \mathrm{L}$ vs $25,8 \mu \mathrm{g} / \mathrm{L})$ siendo significativa esta diferencia $(p=0,04)$. En participantes sanos se observó el mismo efecto $(13,9 \mu \mathrm{g} / \mathrm{L}$ vs. $6,6 \mu \mathrm{g} / \mathrm{L})$. Estos resultados coinciden con la literatura $(21,29,30,35,42)$ : el hidróxido de aluminio en individuos sanos y pacientes en hemodiálisis estaría integrando el metal al organismo vía oral.

Las concentraciones de aluminio en suero pre-HD fueron más altas en el paciente con enfermedad de Alzheimer y aquellos con antecedentes clínicos y familiares de osteoporosis, anemia y problemas renales o dolores óseos, dificultad para la marcha y trastornos de memoria durante el tratamiento con hemodiálisis, al compararlos con pacientes que no refirieron esto; sin embargo, estas diferencias no fueron significativas. Estos resultados concuerdan con lo reportado por otros investigadores $(3,31,41,43-46)$. Los consumidores de bebidas alcohólicas, te y café, así como los usuarios de antitranspirantes presentaron concentraciones de aluminio superiores a los que no consumían dichos productos. Sin embargo, las diferencias en las concentraciones de aluminio encontradas entre unos y otros no fueron significativas $(p>0,05)$ 
Agradecimientos: Los autores agradecen a los pacientes con terapia de reemplazo renal crónico con hemodiálisis y funcionarios del Instituto Nacional de Salud por su participación en el estudio; a los doctores Darío Pardo y Carlos Cristancho por el apoyo técnico y logístico brindado durante el proceso del validación de la metodología; al Dr. Jaime Eduardo Ortiz Varón (q.e.p.d) por la coordinación y orientación técnica en la propuesta del proyecto y al señor Heriberto Morales por su colaboración durante la fase experimental del proyecto.

Conflicto de intereses: Ninguno. Este trabajo fue financiado por el Grupo de Salud Ambiental de la Subdirección Red Nacional de Laboratorios del Instituto Nacional de Salud y cofinanciado por Renal Therapy Services - RTS Limitada.

\section{REFERENCIAS}

1. Fernández-Martín JL, Canteros A, Serrano M, González C, Díaz C, Cannata-Andía JB. Prevention of aluminium exposure through dialysis fluids. Analysis of changes in the last 8 years. Nephrol Dial Transplant 1998;13 [Suppl 3]:78-81.

2. Spencer PS. Aluminum and its compounds. Experimental and Clinical Neurotoxicology. Second edition. Edited by Spencer PS and Schaumburg HH. New York. Oxford University Press; 2000. p.142-151.

3. Cannata-Andía JB, Fernández-Martín JL. The clinical impact of aluminium overload in renal failure. Nephrol Dial Transplant 2002;17 [Suppl 2]:9-12.

4. Fernández-Martín JL, Cannata-Andía JB. Evolución de la concentración de aluminio en la solución final de diálisis: estudio multicéntrico en centro de diálisis españoles. Nefrología 2000;20:342-347.

5. Serrano M, Rodríguez A, González A, Carrillo N, Fernández-Martín JL, Cannata-Andía JB. Análisis evolutivo de la calidad de la solución final de diálisis en España y Portugal. Rev Sc Esp Enferm Nefrol 2006;9:13-18.

6. Canteros A, Díaz-Corte C, Fernández-Martín JL, Gago E, Fernández-Merayo C, CannataAndía JB. Ultrafiltrable aluminium alter very low doses of desferrioxamine. Nephrol Dial Transplant 1998:13:1538-1542.

7. De la Rubia-Comos JM. Determinación de aluminio en líquidos concentrados de hemodiálisis por espectrofotometría de absorción atómica. Memoria para optar al grado de doctor. Universidad Complutense de Madrid. Facultad de Farmacia. Madrid; 2001. p.1-179. ISBN: 84-669-2040-4.

8. Gerstenfeld S, Rodríguez-Rebollar A, Serrano-Arias M, Fernández-Martín JL, CannataAndía JB. Aluminio en solución final de diálisis en centros Portugueses. Estudio multicéntrico. Rev Port Nefrol Hipert 2002;16:83-88.

9. Menéndez-Fraga P, Fernández-Martín JL, Blanco-González E, Cannata-Andía JB. Low percentege of aluminoxamine and ferrioxamine in uremia serum after desferrioxamine administration. Clin Chem 1998; 44:1262-1268.

10. Chícaza L. Fallas del Mercado de la salud en Colombia: el caso de la insuficiencia renal crónica. Revista de Economía Institucional 2005;7:191-207.

11. Toro G, Varona M, Cárdenas O. Neurotoxicidad metales (I parte). Acta Neurol Colom 2000;16:325-335.

12. Fernández-Martín JL, Menéndez-Fraga $P$, Canteros MA, Díaz-López $B$, Cannata-Andía JB. Binding of aluminium to plasma proteins: comparative effect of desferrioxamine and deferiprone (L1). Clin Chim Acta 1994;230:137-145. 
13. Servicio de Salud del Principado de Asturias. Normas para la recogida de sueros, aguas y solución final de diálisis para la determinación de aluminio. Edición 01. Servicio de Metabolismo Oseo y Mineral. Hospital Central de Asturias. Oviedo, Asturias; 2004. p. 1.

14. Ministerio de Salud-República de Colombia. Resolución No. 008430 de 1993. Por la cual se establecen las normas científicas, técnicas y administrativas para la investigación en salud. Ministerio de Salud. Santafé de Bogotá D.C.; 1993. p. 1-13.

15. De Abajo FJ. La declaración de Helsinki VI: Una revisión necesaria, pero ¿Suficiente?. Rev Esp Salud Pública 2001;75:407-420.

16. Nackowski SB. Aluminum in serum. Methods for Biological Monitoring. A Manual for Assessing Human Exposure to Hazardous Substances. First Edition. Edited by Theodore J. Kneip and John V. Crable. American Public Health Association. Washington, DC., 1988;123-126.

17. García M, Terry CC. Características químicas de las aguas destinadas a la hemodiálisis en hospitales de Cuba. Rev Cubana Hig Epidemiol 1997;35:7-10.

18. Sariego-Muñiz C, Fernández-Martín JL, Marchante-Gayón JM, García-Alonso JI, CannataAndía JB, Sanz-Mendel A. Reference values for trace and ultratrace elements in human serum determined by double-focusing ICP-MS. Biol Trace Element Res 2001;81:259-272.

19. Slavin W. Aluminum. Individual Metals. Graphite Furnace AAS a Source Book. Perkin Elmer Corporation. Norwalk, USA; 1984. p.69-74.

20. Bertholf RL, Brown S, Renoe BW, Wills MR, Savory J. Improved determination of Al in serum by electrothermal AAS. Clin Chem 1983;29:1087-1089.

21. Suay L, Ballester F. Revisión de los estudios sobre exposición al aluminio y enfermedad de Alzheimer. Rev Esp Salud Pública 2002;76:645-658.

22. Pérez R, González E, Ceballos F, Escallada R, Gómez Ml, Martín-Rabadán P, et al. Guías de gestión de calidad del líquido de diálisis (LD). Sociedad Española de Nefrología. España; 2003. p.1-80.

23. World Health Organization. Aluminium. Guidelines for drinking-water quality. Third Edition. Geneva. WHO Library Catalougin in Publication data; 2004. p.301-3.

24. Ministerio de la Protección Social, Ministerio de Ambiente, Vivienda y Desarrollo Territorial. Características físicas y químicas del agua para consumo humano, Capítulo II, Artículo 7. Características químicas que tienen consecuencias económicas e indirectas sobre la salud humana. Ministerio de la Protección Social. Resolución 2115 de 2007. Bogotá, D.C.; 2007. p.1-23.

25. Ministerio de la Protección Social. Sistema para la protección y control de la calidad de agua para consumo humano. Ministerio de la Protección Social. Decreto 1575 de 2007. Bogotá, D.C.; 2007. p.1-14.

26. Association for the advancement of Medical Instrumentation. Dialysate for hemodialysis. Arlington; 2004 p.1-77.

27. American National Standards Institute, Inc. Association for the Advancement of Medical Instrumentation. Water treatment equipment for hemodyalisis applications. Arlington; 2001 p. 1-24.

28. León $\mathrm{D}$, Ordoñez $\mathrm{E}$, Muñoz JE, Rodríguez K, Robayo A, Rodríguez R, et al. Guía para el manejo de la enfermedad renal crónica -ERC- Basada en la evidencia. Colombia. Ministerio de la Protección Social, Fundación para la Investigación y Desarrollo de la Salud y la Seguridad Social. Bogotá, D.C; 2005. p.1-56.

29. Fenwick S, Roberts EA, Mahesh BS, Roberts NB. In end-stage renal failure, does infection lead to elevated plasma aluminium and neurotoxicity? Implications for monitoring. Ann Clin Biochem 2005;42:149-52.

30. Van Landeghem GF, D'Haese PC, Lamberts LV, Djukanovic L, Pejanovic S, Goodman WG. Low serum aluminium values in dialysis patients with increased bone aluminium levels. Clin Neprol 1998;50:69-76. 
31. Altmann P, Cunningham J, Dhanesha U, Ballard M, Thompson J, Marsh F. Disturbance of cerebral function in people exposed to drinking water contaminated with aluminium sulphate: retrospective study of the Camelford water incident. BMJ 1999;319:807811.

32. Lin JL, Limp PS, Leu ML. Relationship of body iron status and serum aluminium in chronic renal insufficiency patients not taking any aluminium-containing drugs. Am J Nephrol 1995;15:118-122.

33. Pradilla G. Neurotoxicología del aluminio. Medicas UIS 1989;3:144-146.

34. Cannata-Andía JB. Tratamiento de la intoxicación alumínica: limitaciones de los estudios sobre movilización del aluminio. Nefrología 1993; 13, supl 3:119-122.

35. Serrano M, González A, Douthat W, Acuña G. Fernández-Martín JL, Menéndez P, CannataAndía JB. Control multicéntrico de aluminio en líquidos de diálisis: viabilidad y repercusión sobre los niveles de aluminio sérico. Unidad de Metabolismo Oseo y Mineral. Hospital Central de Asturias. Oviedo; 1994. p.75-8.

36. Fernández E, Macho M, Gómez E, Díaz B, Sánz A, Cannata-Andía JB. Serum aluminium and normal kidney function: effect of age and environmental exposure to aluminium. Rev Clin Esp 1989;185:388-390.

37. Piccoli A, Andriani M, Matiello G, Nordio M, Modena F, Dalla RC. Serum aluminium level in the veneto chronic haemodyalisis population: cross-sectional study on 1206 patients. Nephron 1989;51:482-490.

38. Lin JL, Yang YJ, Yang SS, Leu ML. Aluminum utensils contribute to aluminum accumulation in patients with renal disease. Am J Kidney Dis 1997;30:653-658.

39. World Health Organization. Aluminium. Environmental Health Criteria 194. International Programme on Chemical Safety. Geneva. WHO Library Catalougin in Publication data; 1997. p.1-282.

40. Tahiri Y, Moriniere P, Jaudon MC, DKhissi H, Rosa A, Fournier A. Hyperaluminemia in chronic hemodyalisis patients. Evaluation of the respective roles of dialysate aluminium an oral aluminium hydroxide. Nephrologic 1983:4:129-133.

41. Vick KE, Jonson CA. Aluminium-related osteomalacia in renal-failure patients. Clin Pharm 1985:26:434-439.

42. Parra OE, Navarro JA, De Ardila M, Wessinger J, Domínguez J, Gutiérrez LE. Initial evaluation of aluminium concentrations in patients with nephropathy and undergoing hemodialysis at the Miguel Pérez Carreno Hospital of Caracas (Venezuela). Invest Clin 1989;30:193203.

43. Chu PL, Wu CC, Hsu CJ, Wang YT, Wu KD. Potential ototoxicity of aluminum in hemodialysis patients. Laryngoscope 2007;117:137-141.

44. Friesen MS, Purssell RA, Gair RD. Aluminum toxicity following IV use of oral methadone solution. Clin Toxicol (Phila) 2006;44:307-314

45. Hellström H-O, Mjöberg B, Mallmin $\mathrm{H}$, Michaëlsson $\mathrm{K}$. No association between the aluminium content of trabecular bone and bone density, mass or size of the proximal femur in elderly men and women. BMC Musculoskeletal Disorders 2006;7:69-74.

46. Baquero-Quirós M, Vargas-Rojas R, Blanco-Sáenz R. Neurotoxicidad y enfermedades óseas provocadas por la contaminación con aluminio de soluciones de diálisis renal. Rev Costarric Cienc Med 2001;22:1-11. 